\title{
A STUDY ON AWARENESS ON AB-PMJAY FOR TREATMENT OF DISEASES WITH SPECIAL REFERENCE TO CANCER CARE IN THANJAVUR DISTRICT OF TAMIL NADU
}

\author{
Dr. V.Pugazhenthi \\ Controller of Examinations , \\ Associate Professor\& Head, \\ Research Dept of Commerce \\ Rajah Serfoji Government College, \\ Thanjavur, Tamil Nadu, \\ India.
}

Article DOI: https://doi.org/10.36713/epra6426

\begin{abstract}
BACKGROUND

.Ayushman Bharat or Modicare, the Central Government aims to provide a health insurance cover of Rs 5 lakh to 500 million Indians free of cost. This includes families from lower income groups that fall under the socio-economic caste census (SECC) data of 2011. PM-JAY envisions to help mitigate catastrophic expenditure on medical treatment which pushes nearly 6 crore Indians into poverty each year. In Tamil nadu a scheme called 'Chief Minister Kalaignar's Insurance Scheme for Life Saving Treatments' (KHIS) was launched in the year 2009 to ensure that poor and low income groups who cannot afford costly treatment, are able to get free treatment in Government as well as private hospitals for serious ailments. Later this scheme was modified with extended coverage in the year 2011 and re-launched in the name of 'Chief Minister's Comprehensive Health Insurance Scheme (CMCHIS)'. Under this scheme, the sum assured for each is revised as Rs. 1 lakh every year for a total period of four years and for a total value of Rs. 4 lakh. Now, a value addition is made to the exicting CMCHIS, after the launch of PM-JAY, providing an insurance cover upto Rs 5 lakh per family, per year for secondary and tertiary hospitalization
\end{abstract}

\section{OBJECTIVES}

The objective of this study is to assess the awareness about and attitude towards the AB-PMJAY for treatment of disease especially cancer care. And it also aims to document the efforts taken by the Government of India to spread the awareness to achieve universal health coverage through $A B-P M J A Y$ and to the population.

\section{NEED FOR THE STUDY}

Due to large quantum of people being covered under PM-JAY, there is a strong need to spread awareness with the right message, through the right media and within the right timeframe. The level of awareness about PMJAY scheme and access towards treatment especially cancercare were studied under this research.

\section{METHODOLOGY OF THE STUDY}

The Thanjavur District, one of the 32 Districts in the State of Tamil Nadu, mainly dominated by rural place depending on Agriculture, is taken as the area for the present study. It lies on the east coast of Tamil Nadu, India. The study uses both types of data i.e., primary data and secondary data. The primary data in the form of opinions were collected using structured questionnaire containing various knowledge aspects about AB-PMJAY to assess the awareness from the selected 200 sample beneficiaries following purposive random sampling method and the secondary data were collected from various sources such as books, reports of Government, Ministry of Health, Health Insurance companies, journals, network hospitals and websites. Data collection was done during the month of August 2020.

\section{LIMITATIONS}

This study is related to a particular geographic area namely Thanjavur district. So, few of the findings may not be generalized to the metro cities, wherein the awareness may be comparably higher

\section{CONCLUSION}

Low level of awareness regarding the AB-PMJAY scheme indicates a vital need for formal educational programs to sensitize public regarding the importance of accessing $A B-P M J A Y$ for treatment

KEYWORDS: Health insurance, AB-PMJAY, Cancer care, Cancer Screening;

JEL Classification: I 13, I 18. 
A Study on Awareness on AB-PMJAY for treatment of diseases with special reference to cancer care in Thanjavur District of TamilNadu

The Ayushman Bharat scheme is Prime Minister Narendra Modi's ambitious initiative to evaluate the cost of health services. The Centrallysponsored scheme will provide a free annual cover of up to ₹ 5 lakh a family, of which the State government will bear $40 \%$ of the premium. Ayushman Bharat Pradhan Mantri Jan Arogya Yojana, which provides health insurance cover of Rs. $5,00,000$ to more than 500 million poor and vulnerable persons, was launched on 23rd September 2018.

Ayushman Bharat is an attempt to move from sectoral and segmented approach of health service delivery to a comprehensive need-based health care service. Ayushman Bharat adopts a continuum of care approach, comprising of two inter-related components, which are -

1. Health and Wellness Centres (HWCs)

2. Pradhan Mantri Jan Arogya Yojana (PMJAY)

\section{Health and Wellness Centers (HWCs)}

In February 2018, the Government of India announced the creation of 1,50,000 Health and Wellness Centres (HWCs) by transforming the existing Sub Centres and Primary Health Centres. These centres are to deliver Comprehensive Primary Health Care (CPHC) bringing healthcare closer to the homes of people. They cover both, maternal and child health services and non-communicable diseases, including free essential drugs and diagnostic services.

\section{Pradhan Mantri Jan Arogya Yojana (PM-JAY)}

The second component under Ayushman Bharat is the Pradhan Mantri Jan Arogya Yojna or PM-JAY as it is popularly known. Ayushman Bharat PM-JAY is the largest health assurance scheme in the world which aims at providing a health cover of Rs. 5 lakhs per family per year for secondary and tertiary care hospitalization to over 10.74 crores poor and vulnerable families which was approximately 50 crore beneficiaries that form the bottom $40 \%$ of the Indian population

The households included are based on the deprivation and occupational criteria of SocioEconomic Caste Census 2011 (SECC 2011) for rural and urban areas respectively. PM-JAY was earlier known as the National Health Protection Scheme (NHPS) before being rechristened. It subsumed the then existing Rashtriya Swasthya Bima Yojana (RSBY) which had been launched in 2008. The coverage mentioned under PM-JAY, therefore, also includes families that were covered in RSBY but are not present in the SECC 2011 database. PM-JAY is fully funded by the Government and cost of implementation is shared between the Central and State Governments.

States can implement PMJAY either through the insurance route or the trust route or both. The states implementing the scheme through the insurance mode select the insurance companies through an open tender process. The states implementing the scheme through the trust mode may engage Third-Party Administrators (TPAs) and Implement Support Agencies (ISAs) through an open tender process for implementing the scheme. The cover under the scheme includes all expenses incurred on the following components of the treatment.

Medical examination, treatment and consultation, Pre-hospitalization, Medicine and medical consumables, Non-intensive and intensive care services, Diagnostic and laboratory investigations, Medical implantation services, Accommodation benefits, Food services, Complications arising during treatment, Posthospitalization follow-up care up to 15 days

Tamil Nadu has topped the list in the Ayushman Bharat-Pradhan Mantri Jan Arogya Yojana (AB-PMJAY) in beneficiary enrolment. As of July 2019, the state enrolled 15.7 million families. This was followed by Madhya Pradesh that enrolled 12.8 million families. The scheme, which was launched in September 2018, already reached its target of reaching 500 million in India just within 10 months. According to Union Health Minister Harsh Vardhan As on July 2019, the scheme enrolled 16,039 hospitals, including 8,059 private hospitals and 7,980 public hospitals.

\section{Need for Awareness about AB-PMJAY}

Since PM-JAY is an entitlement-based scheme where there is no advance enrolment process, making beneficiaries aware of the scheme is the most critical aspect. Information, Education and Communication activities were carried out to educate beneficiaries about the scheme. Various modes of communication such as leaflets, booklets, hoardings, $\mathrm{TV}$, radio spots etc are important elements for creating a comprehensive communication strategy for disseminating the desired messages across the target audience.

\section{Steps taken for spreading the Awareness about the Ayushman Bharat scheme}

A detailed communication strategy has been developed by National Health Authority (NHA) which was implemented at both national and State levels. NHA is also working on the overall cooperation \& capacity-building with the States for implementation and development of communication strategy required for increasing awareness at the State level.IEC activities were initiated immediately after the Cabinet approval to the scheme on March, 2019. 
The first major initiative taken was Additional Data Collection Drive (ADCD) drive was undertaken by participating in "Gram Swaraj Abhiyaan" of Ministry of Rural Development on 30th April, 2018 named as "Ayushman Bharat Diwas" with an objective to make people aware about the upcoming scheme benefits and entitlement check by involving ASHA \& ANMs and Gram Sevak covering around 3 lakh villages across the country. Various posters, banners etc. were designed and deployed in Hindi and regional languages across all camps and village meetings for spreading the awareness.

The next initiative taken was Eligible letter was sent to all beneficiary families from Hon'ble Prime Minister, to make them aware about their entitlements under the scheme and also provided them a family card with unique family ID. The letter issued by the Centre to beneficiaries across the State has helped to create awareness, has succeeded in getting people to take note of a scheme

Standardised design materials was prepared by NHA that are being used by States for making beneficiaries aware about the scheme. Various communication channels like print media, television, radio, social media etc. are being used to reach beneficiaries and other stakeholders.

A communication strategy and IEC guidebook has also been developed for this purpose. A dedicated web portal for the scheme www.pmjay.gov.in has been also created to provide all the details about the scheme to various stakeholders. All relevant information and links, e list of empanelled hospitals, Am I eligible portal, grievance redressal portal, gallery, operational guidelines are placed

Table No.1 Table showing the Assessment of the Awareness about AB-PMJAY

\begin{tabular}{|c|c|c|c|}
\hline No & Particulars & $\begin{array}{c}\text { Aware } \\
\%\end{array}$ & $\begin{array}{c}\text { Unaware } \\
\%\end{array}$ \\
\hline 1a) & $\begin{array}{l}\text { Awareness regarding Coverage: } \\
\text { Do you know that the State's CMCHIS health scheme has been integrated with } \\
\text { the Centre's Ayushman Bharat (Pradhan Mantri Jan Arogya Yojana - PMJAY), } \\
\text { and offers a cover of up to ₹5 lakh instead of earlier amount of ₹1-2 lakh }\end{array}$ & $42 \%$ & $58 \%$ \\
\hline 1b) & $\begin{array}{l}\text { Do you know that Benefits of the scheme are portable across the country i.e. a } \\
\text { beneficiary can visit any empanelled public or private hospital in India to avail } \\
\text { cashless treatment. }\end{array}$ & $23 \%$ & $77 \%$ \\
\hline 2a) & $\begin{array}{l}\text { Awareness regarding Authorisation Card: } \\
\text { Do you know for emergency cases, there is a provision for hospitals to proceed } \\
\text { with pre-authorisation without the card, which, when issued, can be } \\
\text { subsequently submitted }\end{array}$ & $20 \%$ & $80 \%$ \\
\hline 2b) & $\begin{array}{l}\text { Are you aware that in Tamil Nadu, the card is issued only at the District } \\
\text { Collector's office }\end{array}$ & $38 \%$ & $62 \%$ \\
\hline 2c) & $\begin{array}{l}\text { Are you aware about a beneficiary can produce the CMCHIS card to claim } \\
\text { benefits under Ayushman }\end{array}$ & $35 \%$ & $65 \%$ \\
\hline 2d) & $\begin{array}{l}\text { Do you know if card is not available, on the CMCHIS website under the } \\
\text { beneficiary/member ID tab, a person can check eligibility using either the URN } \\
\text { number mentioned on the CMCHIS card or ration card number }\end{array}$ & $26 \%$ & $74 \%$ \\
\hline 2e) & $\begin{array}{l}\text { Do you know with income certificate and ration card one can apply and collect } \\
\text { new e - health insurance card from District Collector's office immediately. }\end{array}$ & $29 \%$ & $71 \%$ \\
\hline 3a) & $\begin{array}{l}\text { Awareness regarding PMAM: } \\
\text { Do you know that each empanelled hospital appoint a dedicated staff who are } \\
\text { called Pradhan Mantri Arogya Mitras (PMAMs) and their role is to facilitate } \\
\text { treatment of beneficiaries at the hospitals. }\end{array}$ & $21 \%$ & $79 \%$ \\
\hline b) & $\begin{array}{l}\text { Are you aware that AB PM-JAY beneficiaries will be able to avail services in ESIC } \\
\text { empanelled hospitals }\end{array}$ & $17 \%$ & $83 \%$ \\
\hline 4 & $\begin{array}{l}\text { Do you know that AB-PMJAY scheme covers up to } 3 \text { days of pre-hospitalization } \\
\text { and } 15 \text { days post-hospitalization expenses }\end{array}$ & $29 \%$ & $71 \%$ \\
\hline 5 & $\begin{array}{l}\text { Awareness regarding NAFU; } \\
\text { Are you aware of the fact that preventing, detecting and deterrence of fraud } \\
\text { and abuse under PM-JAY was the primary responsibility of National Anti Fraud } \\
\text { Unit (NAFU) }\end{array}$ & $12 \%$ & $88 \%$ \\
\hline 6 & $\begin{array}{l}\text { Awareness regarding Grievance redressal; } \\
\text { Do you know that using AB PMJAY Call center/ helpline,sending letter, making } \\
\text { telephone calls sending e-mail, and fax to the official addresses of the NHA can } \\
\text { redress the grievances. }\end{array}$ & $15 \%$ & $85 \%$ \\
\hline
\end{tabular}


Source: Primary data

From the above table it is clear that level of awareness about Monitoring the execution of the scheme is very low and which was followed by functioning of Grievance redressal system whereas comparatively higher level of awareness was documented for coverage amount of the scheme and issuance of benefit card .To summarise, though efforts were taken by both the Governments for this scheme, still it finds very low especially Thanjavur like rural based areas need more effort. Because the success of the scheme itself depends on the awareness about various components of the scheme by the beneficiaries.

\section{AB-PMJAY in Treatment of Diseases}

Treatment under AB-PMJAY include Services of approximately 1,393 procedures which cover all the costs related to treatment, including but not limited to drugs, supplies, diagnostic services, physician's fees, room charges, surgeon charges, OT and ICU charges etc. Public hospitals are reimbursed for the healthcare services at par with the private hospitals.

According to Dr Indu Bhushan, CEO of National Health Authority, a large number of cancer cases go untreated every year, especially among the poor and a clear strategy for early detection and provision of affordable and quality cancer care is needed. One major challenge is to increase the availability of quality cancer care facilities across the country, especially in the northern states. The Government was tried to crack down on fraudulent activities and also imposed penalties on hospitals or insurers in indulging in malpractices.

\section{Cancer care treatment by Health and Wellness centre (HWC) in AB-PMJAY}

According to Union Health Ministry every year there are 11.57 lakh new cancer patients in India and 7.84 lakh cancer deaths. At any given point, there are 22.5 lakh Indians living with cancer. India has large unmet cancer treatment facilities is fairly well known and with many reaching hospitals at an advanced stage, which makes treatment unaffordable, only adds to the cancer mortality figures.

Health and wellness centres (HWC), was started for screening of three types of cancer such as oral, cervical and breast for the purpose of identifying and starting the treatment of cancer at earlier stages.

Table No.2 Table showing Cancer care treatment by Health and Wellness Centre (HWC) in ABPMJAY until August 2019.

\begin{tabular}{|c|c|c|}
\hline Types of Cancer & $\begin{array}{c}\text { Number of Cancer } \\
\text { Screening tests }\end{array}$ & $\begin{array}{c}\text { Number of patients Treated } \\
\text { for Cancer }\end{array}$ \\
\hline Oral cavity cancer Screening & $76,00,000$ & 10,218 \\
\hline Breast cancer Screening (W) & $53,00,000$ & 9,700 \\
\hline Cervical cancer Screening(W) & $37,00,000$ & 10,000 \\
\hline
\end{tabular}

As HWCs become operational, a significantly large number of cancer cases detected. In addition, with PMJAY getting mainstreamed, demand for treatment including cancer expanded and in the number of cancer treatments especially among the poor increased hugely. Tamil Nadu tops the list in AB-PMJAY cancer care beneficiaries. More than 1,000 hospitals are empanelled with the NHA for cancer care. Radiation oncology packages were the third-most claimed under tertiary care packages and medical oncology is the sixth-most claimed. The other top tertiary care packages are for cardiovascular diseases, orthopaedics and urology.

\section{AB-PMJAY in cancer care treatment of Tamil Nadu}

Union Health Ministry also documented that, in its first year, the Pradhan Mantri Jan Arogya Yojana (PMJAY), the tertiary care arm of Ayushman Bharat, has funded the treatment of 90,000 cancer patients through 1.8 lakh hospital admissions.
Tamil Nadu where the most cancer patients availed treatment under PMJAY, with 40,056 cancer cases, tops the list, followed by 22,000 cases in Kerala, 19,455 cases in Madhya Pradesh, followed by 15,997 cases in Chhattisgarh and Gujarat with 14,380 cases. Officials say the figures reflect not just cancer incidence in these states but also the availability of treatment facilities and performance of PMJAY in these states. The cancer care claims under PMJAY show a steep rise over the past year. At the launching period that is during September 2018 there were 906 hospitalisation claims across the country for cancer. But during the next year September 2019, the figure was 87,382 .

The NHA is responsible for the implementation of PMJAY under which 10.74 crore families will be entitled to an annual health cover of Rs 5 lakh per family. Until now, of the intended 50 crore beneficiaries, over 10 crore e-cards have been issued.

The National Health Authority (NHA) has so far sanctioned Rs 321 crore for cancer care. Of the total cancer packages claimed, 30,376 are for cancer 
of the reproductive system such as the cervix, ovary, testes etc. 28,506 breast cancer packages have been claimed while PMJAY has funded treatment of 21,379 GI cancer cases and 14,639 of blood and blood vessels and these figures are in line with cancer incidence in the country.

\section{CONCLUSION}

From the above discussions it is very imperative that creating awareness about the various components of AB-PMJAY is very much needed. The duty of the Government does not end by just by implementing health insurance schemes. The health system should be regulated and higher amount of transparency and standardization needs to be ensured. Because in the words of Elizabeth Edwards "Successful health reform must not just make health insurance affordable, affordable health insurance has to make health care affordable". The outcome of the present study may help the policy makers to review the existing system constructively, ensuring more transparency and effectiveness and to attain the dream of providing UHC through Ayushman Bharat without any compromises.

Acknowledgement: This research paper is part of the work of the Major Research Project funded by Indian Council for Social Science Research.(ICSSR),NewDelhi.

\section{REFERENCES}

1. LaForgia,Gerard,andSomilNagpal.2012.Govern ment-SponsoredHealth Insurancein India: AreYou Covered?Directions inDevelopment. Washington, DC:WorldBank.

2. Official website of Pradhan Mantri Jan Arogya Yojana (PM-JAY), Government of India

3. Lucien, G. et al., Separating selection and incentive effects in health insurance.Centre for Economic Policy Research: Great Britain,2005.

4. Pugazhenthi.V. HRM Challenges in Indian Insurance sector, Human Resource Management and TourismDevelopment, 2010, Tichy.pp13-14.

5. Pugazhenthi.V and Sunitha.C, An analysis of claims of Indian health Insurance Industry during 2009-2010. International Journal of Applied Management Research, Volume II,,December 2010 pp642-646..

6. Pugazhenthi.V and Sunitha.C., CRM in Insurance Industry, Smart Journal of Business Management Studies, Vol.2 No.1 January 2006.pp83-88.

7. Pugazhenthi.V and Sunitha.C., Indian Health Insurance plans - A macro level analysis, Research Explorer, Vol.2 Issue 3, February 2013.pp1266-1269.

8. Pugazhenthi.V and Sunitha.C., A study on significance of public health expenditure on health and family welfare, Selp Journal of Social Science, April 2013, Vol.4, Issue 15,pp134-139.

9. Ramanujam P.G., Service Quality in Health Care Organizations: A study of Corporate Hospitals in
Hyderabad, Journal of Health Management, 2011,13(2),pp177-202.

10. Seema Mehta, Service Quality as Predicator of Patient Satisfaction: A Study of the Health Care Sector, Journal of Health Management, 2011,13(2),pp211-229.

11. Sunitha.C., and Pugazhenthi.V., Catastrophe insurance for Gross national happiness, International Journal of Applied Management Research, Volume III,No.2., June 2011 pp.45-52..

12. Sunitha.C., and Pugazhenthi.V. A study on the awareness of Health Insurance among Life insured women, International Journal of Applied Management Research, Volume II,,December 2010 pp590-593. 